\title{
Stimulation and Suppression of
}

\section{Aldosterone in Plasma of Normal Man}

\author{
and in Primary Aldosteronism
}

\author{
R. Horton \\ From the Department of Medicine, University of Southern California, \\ Los Angeles, California 90033, and University of Alabama, \\ Birmingham, Alabama 35233
}

A B S TRACT The effect of stimulating and suppressive influences on plasma aldosterone in normal man and in patients with primary aldosteronism were studied using a sensitive double-isotope derivative assay for aldosterone.

In normal sitting subjects, values were $9.2 \pm 0.9$ (SE) $\mathrm{m} \mu \mathrm{g} / 100 \mathrm{ml}$ and in subjects supine for $1 \mathrm{hr}$ plasma aldosterone was $5.2 \pm 0.4$ ( $\mathrm{sE}$ ) $\mathrm{m} \mu \mathrm{g} / 100 \mathrm{ml}$. Adrenocorticotropic hormone (ACTH), $0.5 \mathrm{U} / \mathrm{hr}$, produced a rise of $46.8 \pm 22$ (SE) $\mathrm{m} \mu \mathrm{g}$ which was similar to the 1-hr effect of an infusion of a synthetic ACTH $\left(\beta^{1-24}\right.$, Cortrosyn). Angiotensin II in pressor amounts also increased plasma aldosterone $21.5 \pm 2.9$ (SE) without change in plasma cortisol, whereas a subpressor dose ( $\left.\frac{1}{3}\right)$ had minimal effect.

Fludrocortisone, $1.2 \mathrm{mg} /$ day for 3 days, suppressed plasma aldosterone levels to $1.8 \pm 0.7$ (SE) $\mathrm{m} \mu \mathrm{g} / 100 \mathrm{ml}$ in five normal sitting subjects $(P<0.01)$; however, dexamethasone, $2 \mathrm{mg} /$ day for 1-2 days, did not lower aldosterone concentration in plasma.

In six patients with primary aldosteronism, plasma aldosterone on a normal sodium diet was $39.1 \pm 4.4$ (SE) which differed significantly from normal sitting or supine subjects $(P<0.001)$. In contrast to the normal subjects, neither a pressor infusion of angiotensin II for $1 \mathrm{hr}$, nor fludrocortisone, $1.2 \mathrm{mg} /$ day for 3 days, impressively altered plasma aldosterone levels.

This approach appears to be useful for the study of the acute physiology and control mechanisms of aldosterone production in normal and hypertensive man.

\section{INTRODUCTION}

Studies of hormone physiology and pathology in man are increasingly requiring methods capable of measuring

Received for publication 5 December 1968. hormone concentration or production rates in blood. This is particularly true in the steroid field since certain steroid hormones in blood can originate from either direct secretion or from peripheral conversion of secreted precursors $(1,2)$. Although there is no evidence that plasma aldosterone arises from other than secreted aldosterone, there is anatomical compartmentalization in the formation of the two major urinary excretion products $(3,4)$. The measurement of urinary aldosterone can in certain situations lead to erroneous conclusions about secretion rates and plasma concentration. The apparent lack of a feedback mechanism based upon aldosterone concentration suggests that a change in metabolic clearance per se could alter plasma concentration without changing urinary excretion or secretion rate (5). Finally, although the excretion of aldosterone metabolites is relatively rapid, urine is ordinarily collected for $24-48 \mathrm{hr}$ for accurate excretion or secretion rate studies (6). A more meaningful approach to the acute physiology of aldosterone requires measurement of the hormone in blood.

Difficult and expensive techniques have been developed for the estimation of aldosterone in plasma (7-9). They have not been adopted for physiological and clinical studies.

Recently, Brodie, Shimizu, Tait, and Tait (10) and, simultaneously, Coghlan and Scroggins (11) have developed more practical, less expensive, but sensitive techniques for the measurement of aldosterone in human and sheep peripheral plasma.

This paper presents our experience with the former method. We have investigated the short-term effects of stimulating and suppressive substances on plasma aldosterone in normal subjects and in patients with primary aldosteronism. 


\section{METHODS}

Plasma aldosterone was measured using the double-isotope derivative assay of Brodie et al. (10). The following information details particulars, minor modifications, and practical experience with this method.

The $4-{ }^{14} \mathrm{C}$ aldosterone indicator (New England Nuclear Corp.), specific activity $55 \mathrm{mc} / \mathrm{mmole}$, was purified as suggested in the original report. Its specific activity was checked by comparison of $20 \mathrm{~m} \mu \mathrm{g}$ of calculated ${ }^{14} \mathrm{C}$ indicator with the amount determined by running the sample through the method, and the sample served as a standard. $1 \mathrm{~m} \mu \mathrm{g}$ of indicator was added to actual samples.

The acetic anhydride- ${ }^{8} \mathrm{H}$ (Nuclear-Chicago Corporation), specific activity $800 \mathrm{mc} / \mathrm{mmole}$, was obtained periodically in 200 -mc amounts, as a $5 \%$ solution in anhydrous benzene $(0.50 \mathrm{ml})$. The reagent was initially quadruple distilled before use and then double distilled each week in a closed glass manifold at $<100 \mu$ vacuum under a high-flow hood used specifically for this purpose. $10 \mu 1$ were then transferred with disposable lambda pipettes (disPo, Scientific Products) into each prepared sample. (Cost was $\$ 3.00$ per sample.) The stated specific activity of the reagent was verified by running a $20 \mathrm{~m} \mu \mathrm{g}$ aliquot of authentic aldosterone, determined gravimetrically and by UV absorption ( $\Delta 240 \mathrm{~m} \mu=$ 16,600 ), before appropriate dilution, through the method. This served as a standard for each reagent batch. The determined specific activity was $98 \pm 2 \%$ of stated activity.

The plasma sample $(10-20 \mathrm{ml})$ with ${ }^{14} \mathrm{C}$ indicator was extracted with double-distilled, charcoal-adsorbed, spectrograde methylene dichloride (Matheson, Coleman and Bell) which was washed and partitioned as originally described (10). The ethanol used in preliminary work up before acetylation (Gold Seal, U. S. Chemical Ltd.) was double distilled before use. This was necessary to control the nonspecific blank of the method.

Carrier aldosterone 21-monoacetate and aldosterone 18, 21diacetate was obtained commercially (Sigma Chemical Co.) and originally purified through column chromatography as described by Brodie et al. (10). Further experience indicated no apparent change in the method blank when the carrier was used without further purification.

The two rapid thin-layer chromatography steps were performed as originally described. The Bush type paper chromatography system was run for $15 \mathrm{hr}$ (5 p.m. to 8 a.m.) after a $2 \mathrm{hr}$ equilibration, eliminating the need for automatic starting equipment which can malfunction. This, together with a $16 \mathrm{hr}$ chromatography in the final reverse phase system, resulted in longer runs of the samples on paper which probably acounts for the lower recovery $(18 \pm 4 \%)$. However, with somewhat higher counting efficiency, the number of ${ }^{14} \mathrm{C}$ and ${ }^{8} \mathrm{H}$ counts in a typical sample and counting errors were quite similar to the original report. The mobile phase in the paper chromatography tanks was drained after each run through an outlet placed into the bottom of the tank. Elution of samples from paper chromatograms was simplified after concentration at the apex as originally described, by elution with a syringe attached to a needle inserted into the proximal part of the cut-out paper pentagon. Final eluted and dried samples were counted, and calculations were performed as originally described. External standardization was used as a check on sample quenching. Samples were counted for $40 \times 5 \mathrm{~min}$ (Mark 1, Nuclear-Chicago Corporation, set for $-10^{\circ} \mathrm{C}$ ). Settings for the ${ }^{8} \mathrm{H}$ channel gave ${ }^{8} \mathrm{H}$ and ${ }^{14} \mathrm{C}$ efficiencies of 18.5 and $9 \%$, respectively, background $10.5 \mathrm{cpm}$, and for the ${ }^{14} \mathrm{C}$ channel, ${ }^{14} \mathrm{C}$ and ${ }^{8} \mathrm{H}$ efficiencies of
48 and $0.01 \%$ respectively, background $8.2 \mathrm{cpm}$. Indicator standards were made up with each week's run.

The nonspecific (water) blank of the method after establishment of the technique in our laboratories was $0.10 \pm$ $0.07 \mathrm{~m} \mu \mathrm{g} / 20 \mathrm{ml}(\mathrm{n}=35)$. All values in the study were corrected for the mean blank of the method. Plasma from two adrenalectomized patients could not be distinguished from blank values ( 0.18 and $0.000 \mathrm{~m} \mu \mathrm{g} / 20 \mathrm{ml}$ of plasma). $20 \mathrm{~m} \mu \mathrm{g}$ of $d$-aldosterone (Steraloids Inc.), purified by column chromatography and determined gravimetrically and by UV absorption before appropriate dilution, gave essentially an identical figure when analyzed in the method $(19.4 \mathrm{~m} \mu \mathrm{g})$.

The angiotensin pressor infusions were performed as described by Kaplan (12). Angiotensin II (CIBA Pharmaceutical Co.) was diluted with $5 \%$ dextrose in water to 1 $\mu \mathrm{g} / \mathrm{ml}$ and administered with a constant infusion pump through Teflon tubing, into the median basilic vein of the arm for 1-2 hr. The infusion rate was adjusted to maintain a $20 \mathrm{~mm}$ elevation in diastolic pressure from the baseline.

The subpressor infusion of angiotensin was performed by administering an amount (usually $\frac{1}{3}$ pressor dose previously determined in the patient) which did not elevate the systolic or diastolic pressure when using a standard cuff manometer.

ACTH (The Upjohn Co.) or synthetic ACTH $\left(\beta^{1-24}\right.$, Cortrosyn, Organon) in $5 \% \mathrm{D} / \mathrm{W}$ (dextrose in water) was infused at a rate of 0.5 unit equivalents $/ \mathrm{hr}(0.5 \mathrm{mg})$, an amount known to maximally stimulate adrenal cortisol secretion in man (13). The manufacturer stated that $5 \mu \mathrm{g}$ Cortrosyn was equivalent to 0.5 IU of ACTH.

The angiotensin and ACTH infusions were administered to the patient in the supine position, after a $1 \mathrm{hr}$ equilibration.

Exogenous mineralocorticoid was given in the form of $9 \alpha$-fluorohydrocortisone (Florinef, E. R. Squibb \& Sons) $0.3 \mathrm{mg} \mathrm{q} 6 \mathrm{hr}$ orally for 3 days.

Glucocorticoid was given in the form of dexamethasone (Decadron, Merck Sharp \& Dohme). For the short-term effect, the subject took $2 \mathrm{mg}$ at 11 p.m.; the long-term effect was tested by giving $0.5 \mathrm{mg}$ every $6 \mathrm{hr}$ for $48 \mathrm{hr}$. For the oral steroid studies, baseline and study plasmas were drawn between 8 and 9 a.m. with the subject in the sitting position after a $1 \mathrm{hr}$ equilibration. Plasma cortisol was measured in the angiotensin and ACTH studies using the binding method of Nugent and Mayes (14).

Normal volunteer subjects (ages 21-30 yr) and patients with primary aldosteronism were on unrestricted diets which, by interview, included 8-13 $\mathrm{g}$ of salt/day.

Six patients with primary aldosteronism were available for study during this period. All had diastolic hypertension with minimal retinal vasculopathy, hypokalemic alkalosis, relative renal potassium wasting, and significant reversal of signs and symptoms on spirolactone (Aldactone, G. D. Searle \& Co.). Intravenous pyelography revealed normal kidney size and function. To date five have had surgery for removal of a typical aldosteronoma. The fourth patient (G. M.) has had complete reversal of electrolyte and pressor abnormalities with spirolactone and has refused surgery. In one $(H . H$.$) , only the baseline plasma was available$ before surgery.

\section{RESULTS}

Baseline plasma aldosterone in normal subjects. Plasma aldosterone values (corrected for mean blank), taken from patients in the sitting position for $1 \mathrm{hr}$ were $9.2 \pm 3.1$ (SD) \pm 0.9 ( $\mathrm{SE}$ ) $\mathrm{m} \mu \mathrm{g} / 100 \mathrm{ml}$, range 5-15.7, $\mathrm{n}=12$. Values from normal subjects in the supine posi- 
TABLE I

The Effect of Angiotensin II and ACTH Infused for $1 \mathrm{hr}$ and Fludrocortisone or Dexamethasone Orally for 1-3 days on Plasma Aldosterone in Normal Subjects

\begin{tabular}{|c|c|c|c|}
\hline No. & Name & Baseline & \\
\hline & & $m \mu g / 100 m l$ & \\
\hline & & Supine & ACTH, $0.5 \mathrm{U} /$ hour \\
\hline 1 & $\mathbf{H}$ & 6.3 & 70.8 \\
\hline 2 & $\mathbf{R}$ & 2.0 & 8.0 \\
\hline 3 & $\mathbf{W}$ & 6.0 & 35.0 \\
\hline 4 & $\mathbf{B}$ & 2.6 & 23.8 \\
\hline \multirow[t]{2}{*}{5} & $\mathbf{N}$ & 7.1 & 96.5 \\
\hline & & & ACTH, $\beta^{1-24}$ \\
\hline 6 & $\mathbf{F}$ & 5.9 & 40.0 \\
\hline 7 & $\mathbf{R}$ & 5.9 & 52.5 \\
\hline \multirow[t]{2}{*}{8} & $\mathbf{H}$ & 6.1 & 100.4 \\
\hline & & & Angiotensin II, 6-12 $\mathrm{m} \mu \mathrm{g} / \mathrm{kg}$ per $\mathrm{min}$ \\
\hline 9 & Mc & 6.4 & 12.0 \\
\hline 10 & B & 6.1 & 13.3 \\
\hline 11 & F1 & 3.0 & 17.2 \\
\hline 12 & Fo & 5.8 & 15.3 \\
\hline 13 & Ho & 6.3 & 18.2 \\
\hline 14 & $\mathbf{F}$ & 5.8 & 27.9 \\
\hline 15 & W & 8.5 & 30.5 \\
\hline 16 & Fr & 6.0 & 38.1 \\
\hline \multirow[t]{2}{*}{17} & $\mathbf{H}$ & 6.8 & 21.4 \\
\hline & & & Angiotensin II, 2-4 $\mathrm{m} \mu \mathrm{g} / \mathrm{kg}$ per $\mathrm{min}$ \\
\hline 18 & $\mathbf{W}$ & 8.0 & 12.4 \\
\hline 19 & $\mathrm{Fr}$ & 8.1 & 10.5 \\
\hline \multirow[t]{2}{*}{20} & $\mathbf{H}$ & 7.9 & 8.3 \\
\hline & & Sitting & Fludrocortisone, $1.2 \mathrm{mg} /$ day \\
\hline 21 & B1 & 9.1 & 0 \\
\hline 22 & $\mathbf{H}$ & 8.3 & 0 \\
\hline 23 & Fo & 10.1 & 2.4 \\
\hline 24 & Fl & 8.0 & 2.9 \\
\hline 25 & Ho & 7.6 & 2.9 \\
\hline \multirow[t]{2}{*}{26} & L & 15.7 & 2.8 \\
\hline & \multicolumn{3}{|r|}{ Dexamethasone } \\
\hline 27 & $\mathbf{H}$ & 5.9 & $4.3^{*}$ \\
\hline 28 & $\mathbf{R}$ & 9.8 & $10.3^{*}$ \\
\hline 29 & $\mathrm{~s}$ & 7.6 & $6.6 \ddagger$ \\
\hline 30 & Fo & 9.1 & $7.3 \ddagger$ \\
\hline
\end{tabular}

* $1 \mathrm{mg}$ at 11 p.m.

$¥ 2 \mathrm{mg} /$ day for 2 days in divided doses.

tion for $1 \mathrm{hr}$ were $5.2 \pm 1.8$ (SD) \pm 0.41 (SE) $\mathrm{m} \mu \mathrm{g} / 100$ $\mathrm{ml}$, range $2.0-8.5, \mathrm{n}=20$. These values do not differ significantly from those in the original report (10); although the mean values in the sitting and supine position do differ, the significance of this difference was not high $(P=0.1)$. There was no apparent change in supine values between 1 and $2 \mathrm{hr}(5.8,5.6$, and 2.0, 3.0 $\mathrm{m} \mu \mathrm{g} / 100 \mathrm{ml}$, respectively, in two subjects).

Effect of ACTH on plasma aldosterone in normal subjects. ACTH (The Upjohn Co.) was infused into five normal supine subjects (Table I and Fig. 1). An impressive rise in plasma aldosterone occurred within $1 \mathrm{hr}$. The mean response was a tenfold rise in plasma aldosterone concentration $(P<0.001)$. Subject B experienced a further increase in plasma aldosterone when the ACTH infusion was expanded to $2 \mathrm{hr}$ ( 23.8 and 49 $\mathrm{m} \mu \mathrm{g} / 100 \mathrm{ml}$ respectively). In order to verify the stimulus as ACTH and not another pituitary or hypothalamic factor, a synthetic polypeptide with high ACTH activity was administered to three subjects. $10 \mu \mathrm{g}$ of Cortrosyn $\beta^{1-24}$ (Organon Inc.), stated to be equivalent to one IU of standard ACTH, were infused. There was a mean 11-fold rise in plasma aldosterone at $1 \mathrm{hr}$, and in one subject $(F)$ an eightfold rise occurred after a 2 $\mathrm{hr}$ infusion. Both preparations of ACTH caused a 3- to 6-fold increase in plasma cortisol.

Effect of angiotensin II in normal supine man. Pressor infusions were performed in nine subjects (Table I and fig. 1). Baseline supine values in these subjects were $6.1 \pm 3.5$ (SE) $\mathrm{m} \mu \mathrm{g} / 100 \mathrm{ml}$. In all nine individuals, there was a rise in plasma aldosterone within $1 \mathrm{hr}$, averaging $350 \%$ (minimum $187 \%$ ) over their baseline value $(P<0.001)$. The infusion was carried out in subject $\mathrm{Ho}$ for an additional hour with little change (18.2 and $20.3 \mathrm{~m} \mu \mathrm{g} / 100 \mathrm{ml}$ ). After a $1 \mathrm{hr}$ infusion, there was no increase in plasma cortisol. No side effects whatsoever were observed. Blood pressures were carefully monitored. The amount of angiotensin II required to maintain diastolic pressure at $20 \mathrm{~mm} \mathrm{Hg}$ over the baseline reading was $6-12 \mathrm{~m} \mu \mathrm{g} / \mathrm{kg}$ per min.

In three subjects previously infused with a pressor dose of angiotensin, the effects of a subpressor dose were studied. One third of a pressor dose $(2-4 \mathrm{~m} \mu \mathrm{g} / \mathrm{kg}$ per $\mathrm{min}$ ) did not measurably elevate the systolic or diastolic pressure when using a cuff manometer. This subpressor amount of angiotensin had minimal effect upon plasma aldosterone $(+30 \%)$, which approaches the error of estimation at that level.

Effect of exogenous mineralocorticoid in normal subjects. Fludrocortisone ( $9 \boldsymbol{\alpha}$-fluorohydrocortisone) was administered orally to six normal subjects in doses of $1.2 \mathrm{mg} /$ day $(0.3 \mathrm{mg}$ every $6 \mathrm{hr})$. The baseline values of subjects in the sitting position were $9.8 \pm 1.6$ (SE) $\mathrm{m} \mu \mathrm{g} /$ $100 \mathrm{ml}$ of plasma. After 1 day of this mineralocorticoid, only minimal change in plasma aldosterone was noted. 3 days of this oral mineralocorticoid resulted in a 3-5 $\mathrm{lb}$. weight gain and a plasma aldosterone level of $1.8 \pm 0.7$ (SE) $\mathrm{m} \mu \mathrm{g} / 100 \mathrm{ml}$ (Table I and Fig. 1).

Effect of exogenous glucocorticoid in normal subjects. Dexamethasone was administered both as in the overnight cortisol suppression test and the 2-day low dose suppression test. In the four subjects studied, no significant change occurred in plasma aldosterone values after the overnight suppression test or 2 days of dexamethasone ( $2 \mathrm{mg} /$ day).

Plasma aldosterone in primary aldosteronism. In six hypokalemic patients with primary aldosteronism, the plasma aldosterone on ad lib. sodium diets was $39.1 \pm$ 4.4 (SE) $\mathrm{m} \mu \mathrm{g} / 100 \mathrm{ml}$, range $22-67$ (Table II). These 


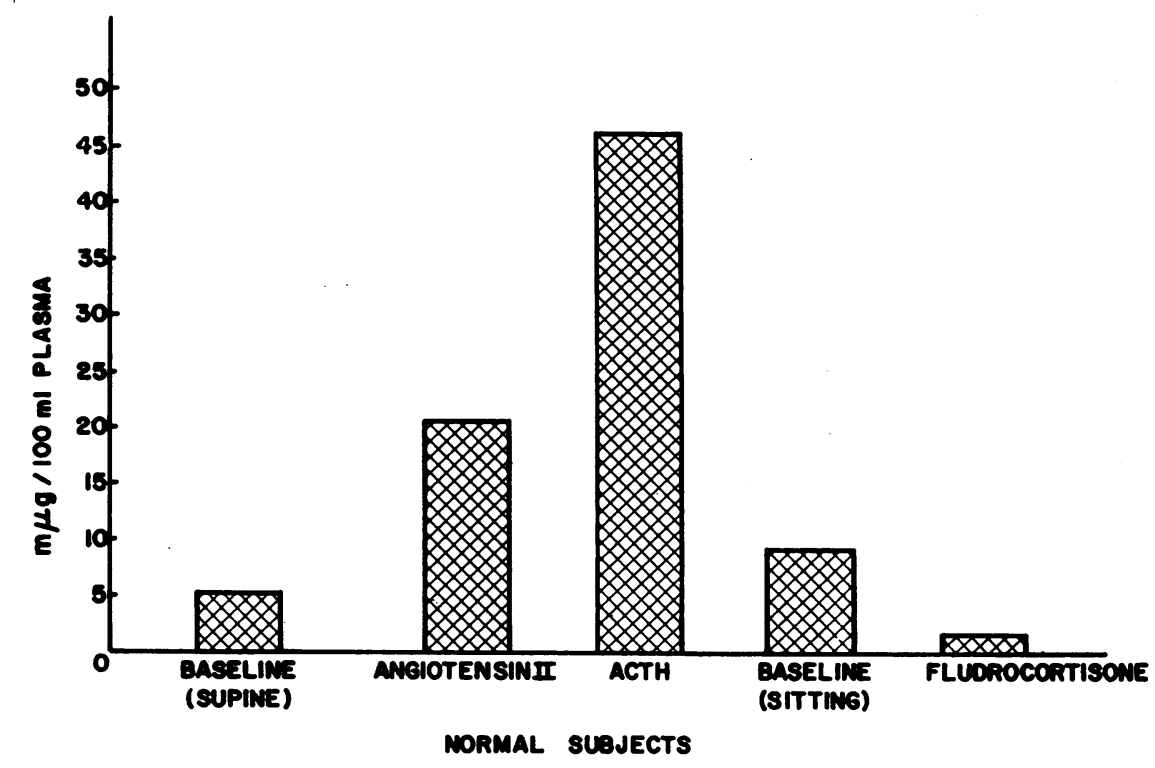

FIGURE 1 The effect of a pressor intravenous infusion of angiotensin II $(6-12 \mathrm{~m} \mu \mathrm{g} /$ $\mathrm{kg}$ per $\mathrm{min})$ or ACTH $(0.5 \mathrm{U} / \mathrm{hr})$ for $1 \mathrm{hr}$ in the supine position and oral fludrocortisone (1.2 mg/day) for 3 days on plasma aldosterone levels in normal subjects.

values significantly differed from normal sitting (or supine) levels on comparable diets $(P<0.001)$. In patient $\mathrm{LeD}$, no change was observed in plasma aldosterone when placed on a $20 \mathrm{gm}$ sodium diet for 3 days ( 67 and $54 \mathrm{~m} \mu \mathrm{g} / 100 \mathrm{ml}$ respectively).

Stimulation in primary aldosteronism with angiotensin. Angiotensin infusion tests were performed in five patients. The pressor dose required to elevate the diastolic pressure $20 \mathrm{~mm} \mathrm{Hg}$ was only $2-4 \mathrm{~m} \mu \mathrm{g} / \mathrm{kg}$ per $\mathrm{min}$. Despite pressor hypersensitivity in these patients; angiotensin II had little or no stimulating effect upon plasma aldosterone. Plasma values did not rise after $1 \mathrm{hr}$ in any of the five patients (Table II and Fig. 2).

Suppression in primary aldosteronism with fludrocortisone. Fludrocortisone (Florinef) did not impres-

\section{TABLE II}

Plasma Aldosterone in Patients with Primary Aldosteronism and the Effect of Pressor Doses of Angiotensin for $1 \mathrm{hr}$ and Oral Mineralocorticoid for 3 days

\begin{tabular}{lllll}
\hline & & \multicolumn{3}{c}{ Primary aldosteronism patients } \\
\cline { 3 - 5 } No. & Name & $\begin{array}{l}\text { Baseline } \\
\text { (supine) }\end{array}$ & $\begin{array}{c}\text { Angio- } \\
\text { tensin }\end{array}$ & $\begin{array}{c}\text { Fludro- } \\
\text { cortisone }\end{array}$ \\
\hline & & & $m \mu g / 100$ & $m l$ \\
1 & LeD & 67 & 57 & 64 \\
2 & G & 20 & 18.4 & 16 \\
3 & J & 22 & 22 & 12.6 \\
4 & G.M. & 36 & 31.9 & 21 \\
5 & F.R. & 51 & 57 & 53 \\
6 & H & 38.6 & & \\
\hline
\end{tabular}

sively lower plasma aldosterone levels in the five patients tested and was not associated with a change in body weight (Table II and Fig. 2), $P>0.2$. In one patient $(\mathrm{J})$ there was a $40 \%$ drop in plasma aldosterone to $12.6 \mathrm{~m} \mu \mathrm{g} / 100 \mathrm{ml}$ after 3 days of high dose fludrocortisone.

\section{DISCUSSION}

Most steroid and polypeptide hormones are secreted in small amounts, have high rates of metabolism (clearance), and are therefore present in peripheral blood in

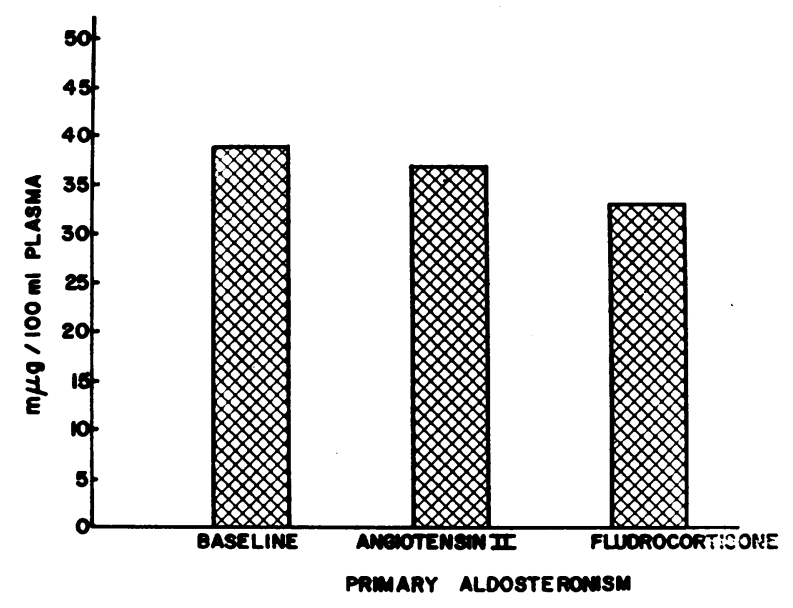

Figure 2 Plasma aldosterone levels in patients with primary aldosteronism and the minimal changes observed after a pressor infusion of angiotensin II $(2-4 \mathrm{~m} \mu \mathrm{g} / \mathrm{kg}$ per $\mathrm{min}$ ) for $1 \mathrm{hr}$ or after 3 days of oral fludrocortisone. 
submicrogram quantities. Until techniques of doubleisotope derivative or displacement analysis were developed, most of these hormones were assayed by their biological effects or in urine.

The secretion rate of aldosterone in man measured by analysis of urinary metabolites under basal conditions and the metabolic clearance in plasma suggested that plasma aldosterone values would be $3-12 \mathrm{~m} \mu \mathrm{g} / 100$ $\mathrm{ml}$ of peripheral plasma (15). Since plasma concentration theoretically can change abruptly or be altered by variations in peripheral metabolism (clearance) without modifying secretion or excretion rates, numerous attempts have been made to measure aldosterone in peripheral plasma. Practicality, cost, and sensitivity have limited their application in the study of human physiology. The recent demonstration by Bledsoe et al. (3) and Cheville et al. (4) that the peripheral metabolism of aldosterone involves formation of the tetrahydrometabolite in the liver, while the acid hydrolyzable compound (aldosterone 18-glucuronide) is made primarily in the kidney, further encourages the development of blood methods.

Two groups have developed simultaneously an acceptable double-isotope method for the estimation of aldosterone in human plasma. These techniques use freshly distilled, high specific activity, tritiated acetic anhydride ( $>500 \mathrm{mc} / \mathrm{mmole})$ and aldosterone $-{ }^{14} \mathrm{C}$ indicator.

We have used the technique of Brodie et al., and have found the method both adequate and reliable for the acute study of aldosterone in human peripheral plasma. This paper presents baseline values in the supine and sitting positions and the effect of stimulating and suppressive influences upon aldosterone production in man.

Baseline supine values are $5.2 \pm 1.8$ (sD) and sitting values are $9.2 \pm 3.1$ (sD) $\mathrm{m} \mu \mathrm{g} / 100 \mathrm{ml}$ of plasma (corrected for the mean blank). This is quite comparable with the values first reported by Brodie et al. of 3.4 (mean of four pools) in the supine position and 7.0 \pm 4 (SD) in the supine position (11). The difference in supine and sitting values may reflect changes in plasma renin possibly reflecting sympathetic activity (16) and/ or fall in aldosterone metabolic clearance rate (17).

$\mathrm{ACTH}$ in near maximal cortisol stimulating dose ( $0.5 \mathrm{unit} / \mathrm{hr}$ ), whether from biological source or in the form of a synthetic polypeptide, appeared to be a profound stimulus which rapidly increased plasma aldosterone concentration in man. A $1 \mathrm{hr}$ infusion resulted in a tenfold rise in plasma aldosterone which, without altering metabolic clearance, would reflect a comparable change in adrenal secretion. Although earlier work on the role of pituitary ACTH indicated that the pituitary was not necessary for aldosterone secretion in various states, recent publications have reiterated the importance of ACTH (18-22). Aldosterone hypersecretion and so- dium conservation are much more effective when the pituitary is intact and is reduced by hypophysectomy. ACTH caused a 2- to 6-fold rise in urinary aldosteron $\epsilon$ ( $\mathrm{pH}-1$ metabolite) on the first day; however, further administration was almost without effect, perhaps as a result of the hypervolemia induced. This demonstration suggested to Liddle, Duncan, and Bartter that a dual mechanism of stimulation existed (23). This subject has been complicated by the recent knowledge of the renin-angiotensin system (24) and by the report that, although the rat pituitary is necessary for aldosterone hypersecretion, no known pituitary hormone could account for the effect of injected pituitary extract (25). Nevertheless, the current study using both ACTH from animal sources and a synthetic ACTH polypeptide, indicated that $\mathrm{ACTH}$ was a profound and rapid stimulus of aldosterone production in man.

Angiotensin II is now a clearly documented stimulus of aldosterone secretion in the normal and sodium-depleted state of the dog and man, usually without change in cortisol secretion (26-28). Ganong, Biglieri, and Mulrow recently reviewed the evidence which relates renal renin production, its effect upon blood pressure, and its ability to stimulate aldosterone production in vitro and in vivo (24). Angiotensin causes a 2 - to 10 fold increase in urinary aldosterone without change in cortisol secretion when infused into normal man or a hypophysectomized dog. In our studies, a moderate pressor dose of $6-12 \mathrm{~m} \mu \mathrm{g} / \mathrm{kg}$ per min of angiotensin II caused a threefold rise in plasma aldosterone in $1 \mathrm{hr}$, but a subpressor infusion had minimal effect. Angiotensin, like $\mathrm{ACTH}$, appeared to have a prompt but possibly less impressive effect upon plasma aldosterone in normal man. The interpretation of the actual degree of stimulation may depend upon the amount of endogenous trophic hormone present. Plasma renin and angiotensin in the supine position on a normal sodium diet are minimal; plasma ACTH levels certainly are not significantly suppressed at 8 a.m. or as part of an infusion procedure.

These studies appear to contain the first reported values of plasma aldosterone in man after ACTH or angiotensin stimulation although Fraser et al., using another method in a preliminary communication, reported prompt elevation of blood aldosterone in one unstressed individual (29).

Volume expansion, high sodium intake, and the effect of exogenous mineralocorticoid, probably all acting through the renin-angiotensin system, are factors which suppress aldosterone secretion in man. Major changes in serum sodium and potassium can also alter aldosterone production (24). Mineralocorticoid administration has been shown to suppress aldosterone production in man $(30,31)$. Biglieri and associates have reported a $70 \%$ fall in urinary aldosterone in normal subjects after 3

\section{R. Horton}


days of parenteral desoxycorticosterone ( $30 \mathrm{mg} /$ day), and this appears to be valuable in the diagnosis of primary aldosteronism (32). In these studies we have used an orally effective mineralocorticoid which has a $1: 1$ potency ratio with aldosterone. Fludrocortisone (1.2 mg daily) had no appreciable effect upon plasma aldosterone after the first day, therefore confirming the data against a mineralocorticoid feedback in man. 3 days of fludrocortisone resulted in a 4-5 lb. weight gain and a drop in plasma aldosterone values to less than $3 \mathrm{~m} \mu \mathrm{g} /$ $100 \mathrm{ml}$. Oral fludrocortisone appears to be a practical test of aldosterone suppressability in man.

Although ACTH may be a major acute stimulus to aldosterone secretion in man, ACTH suppression with a glucocorticoid (cortisol), at least when studied over a 12-24 hr period, had little effect upon aldosterone production - $(23,24)$, except in certain steroid biosynthetic disorders where abnormal mineralocorticoids were under the influence of ACTH $(33,34)$. In our studies on normal subjects, dexamethasone had no appreciable effect upon plasma aldosterone.

These approaches were quite revealing when applied to patients with primary aldosteronism. The plasma values in six patients with primary aldosteronism on normal sodium diets were significantly different from normal values. These values are comparable to those reported by Peterson using a double-isotope method with acetic anhydride- ${ }^{14} \mathrm{C}(9)$. Angiotensin II infusions were administered to five patients and there was pressor hypersensitivity similar to that described by Kaplan (12), presumably caused by minimal endogenous renin production in this state (35). Despite its pressor effects, angiotensin II had no stimulating activity on aldosterone production and plasma aldosterone concentration after $1 \mathrm{hr}$ of infusion. It is possible that higher infusion rates are capable of stimulating the aldosteronoma; however, this was not investigated, since diastolic pressures were elevated $20 \mathrm{~mm} \mathrm{Hg}$ over the baseline by the standard infusion. At the present time, these observations cannot be compared with those of Spark and associates (36), since this group sampled adrenal vein blood, and there may be changes in blood flow and concentration during angiotensin administration. Fludrocortisone had little effect upon plasma aldosterone after 3 days administration. In one patient, a moderate drop appeared; however, the value of $12.6 \mathrm{~m} \mu \mathrm{g} / 100 \mathrm{ml}$ was at the upper limit of normal and more than three times higher than the upper limit observed in normal subjects given fludrocortisone. These observations suggest that fixed secretion rates exist in primary aldosteronism despite angiotensin stimulation or mineralocorticoid administration. The pressor effect of angiotensin persists; however, there appears to be no sustained stimulation of aldosterone secretion from the adrenals of patients with this disorder. It will be interesting to see if such patients would respond to angiotensin if they were hypo- or normovolemic. Further study of angiotensin stimulation must be made in other hypertensive states before the lack of aldosterone hypersecretion after angiotensin can be proposed as a diagnostic test for a functioning aldosteronoma. Biglieri et al. have studied the effect of desoxycorticosterone suppression in essential and renovascular hypertension (32), and found that these patients have a near normal reduction in urinary aldosterone ( $\mathrm{pH}-1$ metabolite), thus suggesting the renin-angiotensin-aldosterone system can be suppressed in these hypertensive states.

These studies represent an attempt to establish baseline, stimulation, and suppression values for plasma aldosterone in subjects on normal, but not rigidly controlled, sodium diets. Under these conditions ACTH and angiotensin II rapidly and impressively stimulate aldosterone secretion in man. Exogenous mineralocorticoid, but not glucocorticoid, can suppress plasma aldosterone, but only after 3 days of therapy.

The validity of using these parameters to study the acute physiology of the renin-angiotensin-aldosterone system in normal and hypertensive man is suggested in primary aldosteronism where aldosterone production (plasma concentration) appears fixed, despite these stimuli.

The introduction of adequate methods for measuring major segments of the renin-angiotensin-aldosterone system in human peripheral blood should allow further extension of our knowledge of the acute physiology and pathophysiology of this important system in man.

\section{ACKNOWLEDGMENTS}

I gratefully acknowledge the helpful advice of Angela Brodie, Ph.D., and James F. Tait, Ph.D., Worcester Foundation for Experimental Biology and Medicine, Shrewsbury, Mass. I was greatly aided in the performance of this work by the able technical assistance of Mrs. T. MacCallum, B.S., and Mrs. S. Speer, B.S.

This work was supported by U. S. Public Health Service Grant AM 12,400.

\section{REFERENCES}

1. Tait, J. F. 1963. Review: the use of isotopic steroids for the measurement of production rates in vivo. $J$. Clin. Endocrinol. Metab. 23: 1285.

2. Tait, J. F., and R. Horton. 1966. The in vivo estimation of blood production and interconversion rates of androstenedione and testosterone. In Steroid Dynamics. G. Pincus, T. Nakao, and J. F. Tait, editors. Academic Press Inc., New York.

3. Bledsoe, T., G. W. Liddle, A. Riondel, D. P. Island, D. Bloomfield, and B. Sinclair-Smith. 1966. Comparative fates of intravenously and orally administered aldosterone: evidence for extrahepatic formation of acidhydrolyzable conjugate in man. J. Clin. Invest. 45: 264. 4. Cheville, R. A., J. A. Luetscher, E. W. Hancock, A. J. Dowdy, and G. W. Nokes. 1966. Distribution, conjuga- 
tion and excretion of labeled aldosterone in congestive heart failure and in controls with normal circulation: development and testing of a model with an analog computer. J. Clin. Invest. 45: 1302.

5. Tait, J. F., J. Bougas, B. Little, S. A. S. Tait, and C Flood. 1965. Splanchnic extraction and clearance of aldosterone in subjects with minimal and marked cardiac dysfunction. J. Clin. Endocrinol. Metab. 23: 219.

6. Kliman, B., and R. E. Peterson. 1961. Double isotope derivative assay of aldosterone in biological extracts. J. Biol. Chem. 235: 1639.

7. Ayres, P. J., O. Garrod, S. A. S. Tait, J. F. Tait, and G. Walker. 1957. The use of $16-{ }^{3} \mathrm{H}$ aldosterone in studies on human peripheral blood. In Hormones in Blood. Little, Brown \& Co., Boston. 10: 309.

8. Bojeson, E., and H. Degn. 1961. A double isotope derivative method for the determination of aldosterone in peripheral plasma. The effect of adrenalectomy on aldosterone level in anaesthetized dogs. Acta Endocrinol. $37: 541$.

9. Peterson, R. E. 1964. Determination of peripheral plasma aldosterone. In Aldosterone. E. E. Baulieu and P. Robel, editors. Blackwell Scientific Publication, Ltd. Oxford. 145.

10. Brodie, A. H., N. Shimizu, S. A. S. Tait, and J. F. Tait. 1967. A method for the measurement of aldosterone in peripheral plasma using ${ }^{3} \mathrm{H}$-acetic anhydride. J. Clin. Endocrinol. Metab. 27 : 997.

11. Coghlan, J. P., and B. A. Scoggins. 1967. Measurement of aldosterone in peripheral blood of man and sheep. J. Clin. Endocrinol. Metab. 27: 1470.

12. Kaplan, N. M., and J. G. Silah. 1964. The effect of angiotensin II on blood pressure in the human with hypertensive disease. J. Clin. Invest. 43: 659.

13. Ney, R. L., N. Shimizu, W. E. Nicholson, D. P. Island, and G. W. Liddle. 1963. Correlation of plasma ACTH concentration with adrenocortical response in normal human subjects, surgical patients, and patients with Cushing's disease. J. Clin. Invest. 42: 1669.

14. Nugent, C. A., and D. M. Mayes. 1966. Plasma corticosteroids determined by use of corticosteroid-binding globulin and dextran-coated charcoal. J. Clin. Endocrinol. Metab. 26: 1116.

15. Tait, J. F., B. Little, S. A. S. Tait, and C. Flood. 1962. The metabolic clearance rate of aldosterone in pregnant and nonpregnant subjects estimated by both single-injection and constant-infusion methods. J. Clin. Invest. 41 : 2093.

16. Cohen, E. L., D. R. Rovner, and J. W. Conn. 1966. Postural augmentation of plasma renin activity. Importance in diagnosis of renovascular hypertension. J. Amer. Med. Ass. 197: 973.

17. Bougas, J., C. Flood, B. Little, J. F. Tait, S. A. S. Tait, and R. Underwood. 1964. Dynamic aspects of aldosterone metabolism. In Aldosterone. E. E. Baulieu and P. Robel, editors. Blackwell Scientific Publications, Ltd. Oxford. 25.

18. Farrell, G. L., E. W. Rauschkolb, and P. C. Royce. 1955. Secretion of aldosterone by the adrenal cortex of the dog. Effects of hypophysectomy and ACTH. Amer. J. Physiol. 182: 273.

19. Muller, A. F., A. M. Riondel, and E. L. Manning. 1956. Effect of corticotrophin on secretion of aldosterone. Lancet. 2: 1021.
20. Venning, E. H., I. Dyrenfurth, C. J. P. Giroud, and J. C. Beck. 1957. Factors affecting aldosterone excretion. Can. Med. Ass. J. 77: 773.

21. Davis, J. O., P. F. Binnion, T. C. Brown, and C. I. Johnston. 1966. Mechanisms involved in the hypersecretion of aldosterone during sodium depletion. Circ. Res. 18: 143.

22. Newton, M. A., and J. H. Laragh. 1968. Effect of corticotropin on aldosterone excretion and plasma renin in normal subjects, in essential hypertension and in primary aldosteronism. J. Clin. Endocrinol. Metab. 28: 1006.

23. Liddle, G. W., L. E. Duncan, Jr., and F. C. Bartter. 1956. Dual mechanisms regulating adrenocortical function in man. Amer. J. Physiol. 21: 380.

24. Ganong, W. F., E. G. Biglieri, and P. J. Mulrow. 1966. Mechanisms regulating adrenocortical secretion of aldosterone and glucocorticoids. Recent Progr. Hormone Res. 22: 381

25. Palmore, W. P., and P. J. Mulrow. 1967. Control of aldosterone secretion by the pituitary gland. Science. 158: 1482 .

26. Mulrow, P. J., and W. F. Ganong. 1960. Stimulation of aldosterone secretion by angiotensin II. Yale J. Biol. Med. 33: 386.

27. Laragh, J. H., M. Angers, W. G. Kelly, and S. Lieberman. 1960. Hypotensive agents and pressor substances. The effect of epinephrine, norepinephrine, angiotensin II, and other on the secretory rate of aldosterone in man J. Amer. Med. Ass. 174: 234.

28. Biron, P., E. Koiw, W. Nowaczynski, J. Brouillet, and J. Genest. 1961. The effects of intravenous infusion of valine- 5 angiotensin II and other pressor agents on urinary electrolytes and corticosteroids, including aldosterone. J. Clin. Invest. 40: 338.

29. Fraser, R., V. H. T. James, J. J. Brown, P. Isaac, A. F. Lever, and J. I. S. Robertson. 1965. Effect of angiotensin and of Furosemide on plasma aldosterone, corticosterone, cortisol, and renin in man. Lancet. 2: 989.

30. Perera, G. A. 1948. Effect of continued desoxycorticosterone administration in hypertensive subjects. Proc. Soc. Exp. Biol. Med. 68: 48.

31. Mills, I. H., and D. W. Barkham. 1962. The effects of $9 \alpha$-fluorohydrocortisone on the response to angiotensin infusions in man. Excerpta Med. Int. Congr. Ser. 51: 221. (Abstr.)

32. Biglieri, E. G., P. E. Slaton, S. J. Kronfield, and M. Schambelan. 1967. Diagnosis of an aldosterone-producing adenoma in primary aldosteronism. An evaluative maneuver. J. Amer. Med. Ass. 201: 510.

33. Sutherland, D. J. A., J. L. Ruse, and J. C. Laidlaw. 1966. Hypertension, increased aldosterone secretion and plasma renin activity relieved by dexamethasone. Can. Med. Ass. J. 95: 1109.

34. Goldsmith, O., D. H. Solomon, and R. Horton. 1967. Hypogonadism and mineralocorticoid excess. The 17. hydroxylase deficiency syndrome. N. Engl. J. Med. 277: 673.

35. Conn, J. W., E. L. Cohen, and D. R. Rovner. 1964. Suppression of plasma renin activity in primary aldosteronism. Distinguishing primary from secondary aldosteronism in hypertensive disease. J. Amer. Med. Ass. 190: 213.

36. Spark, R. F., S. L. Dale, P. C. Kahn, and J. C. Melby. 1968. Activation of aldosterone secretion in primary aldosteronism. J. Clin. Invest. 47: 93a. (Abstr.) 